\title{
Wildland Fire Science Literacy: Education, Creation, and Application
}

\author{
Devan Allen McGranahan $1, *(1)$ and Carissa L. Wonkka ${ }^{2}$ (]) \\ 1 School for Natural Resource Sciences-Range Science Program, North Dakota State University, \\ Fargo, ND 58105, USA \\ 2 Department of Agronomy and Horticulture, University of Nebraska, Lincoln, NE 68583, USA; \\ cwonkka2@unl.edu \\ * Correspondence: devan.mcgranahan@gmail.com or devan.mcgranahan@ndsu.edu; Tel.: +1-701-231-7868
}

Received: 17 October 2018; Accepted: 17 December 2018; Published: 19 December 2018

Abstract: Wildland fire science literacy is the capacity for wildland fire professionals to understand and communicate three aspects of wildland fire: (1) the fundamentals of fuels and fire behavior, (2) the concept of fire as an ecological regime, and (3) multiple human dimensions of wildland fire and the socio-ecological elements of fire regimes. Critical to wildland fire science literacy is a robust body of research on wildland fire. Here, we describe how practitioners, researchers, and other professionals can study, create, and apply robust wildland fire science. We begin with learning and suggest that the conventional fire ecology canon include detail on fire fundamentals and human dimensions. Beyond the classroom, creating robust fire science can be enhanced by designing experiments that test environmental gradients and report standard data on fuels and fire behavior, or at least use the latter to inform models estimating the former. Finally, wildland fire science literacy comes full circle with the application of robust fire science as professionals in both the field and in the office communicate with a common understanding of fundamental concepts of fire behavior and fire regime.

Keywords: environmental education; fire ecology and management; human dimensions of wildland fire; natural resource science and management

\section{Introduction}

Fire is widely recognized as an ecological process integral to ecosystem functioning worldwide. Likewise, widespread appreciation for associations between local biomass burning and global biogeochemical cycling has highlighted the importance of understanding the complexity of fire in the Earth system. Wildland fire science education must prepare future researchers, managers, and policymakers to grapple with such complexity [1]. Wildland fire is a particularly challenging discipline to teach and study because one must scale basic chemical and physical processes (e.g., combustion) up several orders of magnitude in space and time (Figure 1) and apply them across highly variable environments and climates.

Here, we outline a framework to promote wildland fire science literacy: robust wildland fire science education that enhances the capacity of undergraduate and graduate learners to study, understand, and apply the fundamentals of wildland fire under dynamic ecological, environmental, and social conditions. Fire science literacy demands every level of wildland fire science education and practice integrate three key aspects of wildland fire: (1) the fundamentals of fuels and fire behavior, (2) the concept of fire as an ecological regime, and (3) multiple human dimensions of wildland fire and the coupled socio-ecological nature of fire regimes, which is generally lacking in ecological conceptual models of wildland fire (Figure 1). 


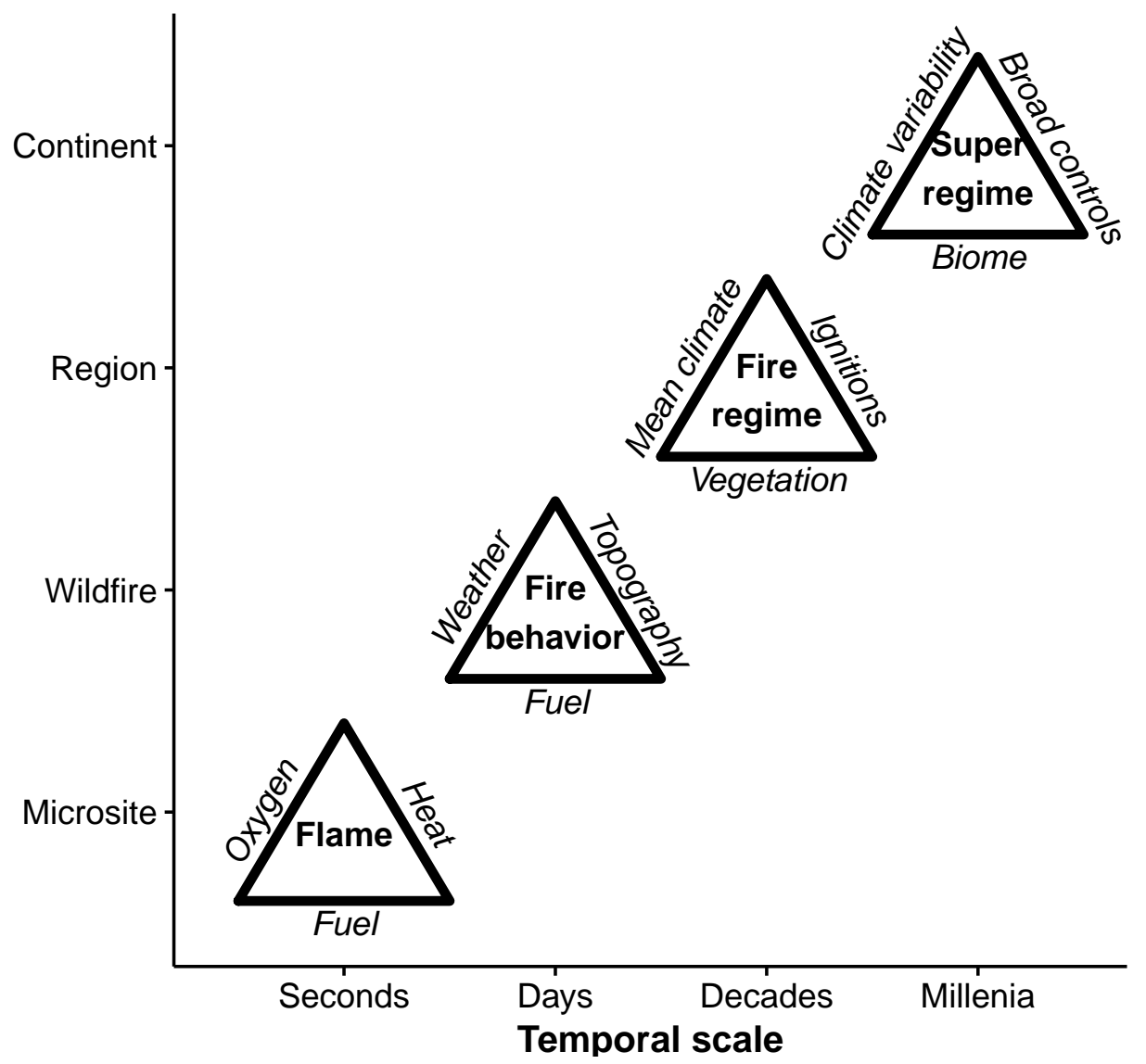

Figure 1. Four scales of control relevant to wildland fire. Many authors represent controls at each scale with triangles; this figure is a modified version of the modified version presented by Scott et al. [2]. While these triangles together encompass most sources of biotic and abiotic variability in the wildland fire environment, the model fails to incorporate human dimensions of wildland fire.

\section{Three Realms of Fire Science Literacy}

Wildland fire science literacy relies upon a robust body of wildland fire science, and it is critical that practitioners, researchers, and other professionals are trained to study, create, and apply the best knowledge available. Here, we consider three realms of fire science literacy: education, the specific parts of the learning experience that takes place in university classrooms; creation, the activities of wildland fire researchers; and application, the work of managers and policymakers.

\subsection{Education}

This perspective focuses on undergraduate and graduate education at universities, where wildland fire science generally appears as "fire ecology" courses in natural resource management programs or in units on disturbance in ecology courses in biology programs. These undergraduate and graduate students will become the wildland fire professionals who will play a prominent role in disseminating an understanding of wildland fire to the general public. Therefore, enhancing literacy in universities is integral to the creation of wildland fire science literacy more generally. In applied programs like forestry and range science, the emphasis might often be on fire as a management option and the potentially destructive impacts of poorly-managed fire on timber or forage resources. In most courses, fire is likely taught in the context of disturbance events that alter succession and community composition, with emphasis on individual traits and behaviors that characterize "fire-adapted" species.

Despite little scholarship on wildland fire education specifically, two approaches from sustainable development education inform teaching and learning of wildland fire science. The first approach 
assumes environmental challenges can be understood through science and that knowledge of facts advances learning; the second approach assumes fundamental social/political problems for which learning is advanced by social science perspectives, critical thinking, and indigenous knowledge $[3,4]$. In wildland fire science, "fire ecology" students must understand both fundamental facts about combustion and heat transfer, fuels, and fire behavior (the first two triangles; Figure 1) and think critically about integrating society with wildland fire in addition to ecological responses to fire as a disturbance.

Advanced sensory equipment reveals the complexity of combustion, heat transfer, and flame propagation, highlighting the variability of these processes in the wildland fire environment $[5,6]$. While modern experimental science generally focuses on controlling variability, it is essential that wildland fire researchers and managers understand the sources and consequences of variability to identify which variables drive responses in a given ecosystem under given conditions. Wildland fire science is at a critical juncture, moving from classical steady-state understandings of combustion and fire spread towards models based on dynamic interactions [1]. Thus, while students can be introduced to the wildland fire environment through steady-state models based on simplified inputs-fuel models, terrain, and weather, for which the Rothermel fire spread equation [7] is a useful heuristic device-students must also appreciate the shortcomings of steady-state models and understand that dynamic interactions in the fire environment drive fire behavior and fire effects [8].

Ensuring that future wildland fire managers, researchers, and policymakers understand the interconnections between human societies and wildland fire is an essential component of wildland fire science literacy. Achieving this requires a transdisciplinary approach that presents wildland fire-related lessons through complex social-ecological systems thinking [9]. Current research suggests that presenting students with the opportunity to explore and reflect on the human dimensions of local environmental problems by interacting with the individuals concerned is the most effective pedagogy for developing critical perspectives that integrate values, ethics, economics, politics, and biophysical understanding of ecological processes [10]. This is challenging as it requires students to overcome educational legacies to think synthetically about the role of humans in shaping the fire environment and ecological responses to wildland fire, as well as engage with a multiplicity of divergent perspectives [11]. Interdisciplinary teaching teams and a diversity of students engaging in dialog and reflection about wildland fire-related issues under a variety of contexts can help foster competence in critical analysis and a multi-perspective comprehension of the complexity of wildland fire problems. This requires a restructuring of traditional modes of science learning (with a focus on presenting the current scientific consensus to students as absolute knowledge) toward a pedagogy that recognizes the role of values in developing a body of knowledge and appreciates the ambiguities arising from the complexity of the coupled human-natural environment [12].

Finally, we suggest educators consider what objectives of hands-on experience are uniquely suited to obtain and tailor experiences to meet those objectives. Traditional natural science courses have long used laboratory-based experiences to teach fundamental skills and demonstrate concepts, although these experiences do not necessarily attain learning objectives more effectively than virtual and online experiences (e.g., $[13,14]$ ). Thus, to be worthwhile expenditures of course time and resources, hands-on experiences must directly serve specific learning objectives, rather than simply be topically related to classroom material. As an example, if a desired objective is to understand first-hand the variability of the wildland fire environment and how managers plan for and adapt to variability in prescribed fire operations, students might get more from observing and listening to radio chatter at a real prescribed burn with full crew and equipment, rather than hands-on participation in small burns on research plots or native plantings around campus.

\subsection{Creation}

Wildland fire science creation bridges education and application by generating the primary knowledge that informs lectures, management plans, and wildland fire policy. Fire science creation 
is also tied to education and application because knowledge gaps identified by managers and policymakers often drive research. As such, wildland fire education should prepare students at the learning phase to conduct robust fire science that maximizes applicability and critically evaluate available fire science. Here, we highlight two fundamental concepts of conducting and reporting research that enhance the interpretation and transferability of wildland fire science.

The first fundamental concept of ecological research to be taught to and modeled for learners of wildland fire science is the value of measuring response variables along environmental gradients [15]. Ecological research typically employs a classical approach to experimental design based on comparing replicated groups-often one or more treatments against an untreated control—with statistics designed to test for an effect based on the probability of difference between group means relative to the spread, or variability, of data values around group means; this is the basic premise of analysis of variance (ANOVA). Under this framework, a "significant" statistical result depends on relatively low variability, which should be of immediate concern for those who conduct, study, and apply research in highly-variable systems like wildland fire because the degree of control one must have over variability to use ANOVA makes the study system much less realistic, and often, the variability itself is an important driver of ecological outcomes.

Furthermore, group-means comparison has a weak capacity to identify the magnitude of a treatment variable's influence on the response, a value known as the "effect size." Sampling along environmental gradients, designing dose-response experiments [16], and testing responses with regression approaches provides insight into how much the response shifts with each increment of the potentially driving variable. When multiple variables are sampled along that same gradient, researchers can compare the relative effect sizes of the variables to identify which of the included variables are most influential with respect to the measured response, allowing for the finding that this importance shifts at different positions along the gradient. When incorporated into a well-designed study, this approach can offer insight into the mechanisms that drive ecological processes, rather than simply describe ecological patterns [17].

A second fundamental concept reaches beyond even the tradition of ANOVA, back to a core principle of the scientific method: reproducibility. While the results of ecological experiments are often context-specific, standard sampling and analytical methods help ensure similarity in the type of data collected and reported across studies. Likewise, there are disciplinary traditions for reporting that assist readers in placing a given study within a broad biogeographic context; two examples from field ecology include giving geographic coordinates, so readers can find the study location on a map, and reporting precipitation, so readers can contextualize responses with regards to one of the main drivers of ecosystem structure and function: primary productivity. While this information does not make a field study as easily reproducible as one conducted on a lab bench, it helps readers infer how the ecological context might bear on the reported results and helps managers understand how the results might translate to other ecosystems.

Wildland fire science would benefit from conventions for data reporting to translate measured responses among study locations. Data sought by systematic reviews and included in meta-analyses can generally guide reporting conventions [18]. Many relevant types of data are already collected in robust experiments that test responses along meaningful environmental gradients; e.g., rather than reporting on "burned" and "unburned" groups, authors should ideally report some measure of fire behavior within each treatment even if the study hypotheses do not directly address fire behavior. When measuring real-time fire behavior is not possible, authors can include data on fuel (load and moisture) and fire weather (wind speed and relative humidity), and even present results of fire behavior models simulating study conditions. Basic fuel data and estimated fire behavior help readers associate measured fire effects with the fire environment, which helps explain variability in fire effects among similar studies. Diamond et al. [19] provided a robust example of how fire behavior data inform specific hypotheses and fuel data inform fire behavior models to predict fire behavior outside of conditions included in a specific study. Finally, including such data increases the value of single 
studies to future systematic reviews and meta-analyses; synthesis in ecology is often hampered by missing data on variables that are important to understanding responses [18].

Robust fire science requires researchers to consider the human context under which their studies are conducted. Humans and their societies have enormous impacts on fire regimes. They alter fuel types, structure, and continuity, exert large control over the number, frequency, and distribution of ignitions, and change the landscape pattern of fire spread and severity through suppression and fuel management [20]. To appreciate ecosystem responses to wildland fire fully, fire science should strive to synthesize knowledge of fire as a fundamental ecosystem process with understanding of the human dimensions of coexisting with wildland fire. Human dimensions are not simply the attitudes of those making management decisions or people affected by those decisions, but rather include the entire scope of human-environment interactions, which varies across cultures and evolves over time as human-environment feedbacks play out. This view of the role of humans in ecological systems has become more prevalent in ecological research generally, as is evidenced by a surge of research on socio-ecological systems and in the application of complex systems science to ecological investigations [9]. Wildland fire research would benefit from following this approach. This likely requires fire scientists to work with interdisciplinary research teams to develop research questions and designs as fire scientists have not traditionally been trained to explore the social-ecological aspects of fire ecology. Wildland fire issues are uniquely suited to such an approach given the pivotal role fire has played throughout human history in the interaction of humans with the natural environment [20].

\subsection{Application}

We summarize the application of robust wildland fire science in a conceptual model that defines two arenas of practice: the field and the office (Figure 2). Wildland fire science literacy facilitates communication between practitioners who specialize in each arena. While overly-simple conceptual models can create bias in the application of scientific information, robust models include major modes, incorporate state changes and transitions, and emphasize changes in disturbance regimes [21]. The two arenas constitute the major modes of wildland fire science application: workers in the field conduct research or management operations, while those in the office write management plans and grant proposals, read and write technical articles, or create policy. The components within each arena reflect those represented in the first three fire triangles: flame, fire behavior, and fire regime (Figure 1). These components form the basis of wildland fire science literacy.

The field arena highlights elements of the fire environment and fire behavior that must be measured and reported to ensure research can be translated and management actions are safe and effective. Fire behavior-ignition, propagation, and spread-occurs at the interface of the fine-scale flame triangle-oxygen, heat, and fuel — and the environmental variables of the landscape-scale fire behavior triangle: weather, fuelbed, and physical features that describe the terrain (Figure 2 left). Each side of the outer (fire behavior) triangle in Figure 2 includes several variables whose measurement and inclusion facilitate robust fire science. These data aid in the interpretation and transferability of wildland fire research, as they provide important context about the fire environment and fire behavior to support better interpretation and application of results.

The office arena outlines several social and ecological components of the fire regime that are essential to interpreting results, planning research, and formulating policy (Figure 2 right). The connection between the two arenas occurs at the center, where fire behavior response variables-intensity, extent, and rate-of-spread-interact with broad components of the socio-ecological fire regime. When interpreting prior research, readers must consider the abiotic and biotic context of the study at hand. When planning new research or applying existing knowledge in management activities, not only must the abiotic and biotic factors of the focal ecosystem be considered, but several human dimensions must also be taken into account. For example, the prescribed fire culture in the Great Plains of North America largely calls for dormant season burns despite considerable evidence that pre-settlement fire regimes included substantial growing season fire, and growing season burns 
advance both ecological and economic objectives [22,23]. More broadly, attention to the nuances of fire type and season within a given vegetation complex is not only critical for effective policy and clear communication with the general public, but such specificity allows those in the office to clearly communicate management objectives and research priorities to those operating in the field.
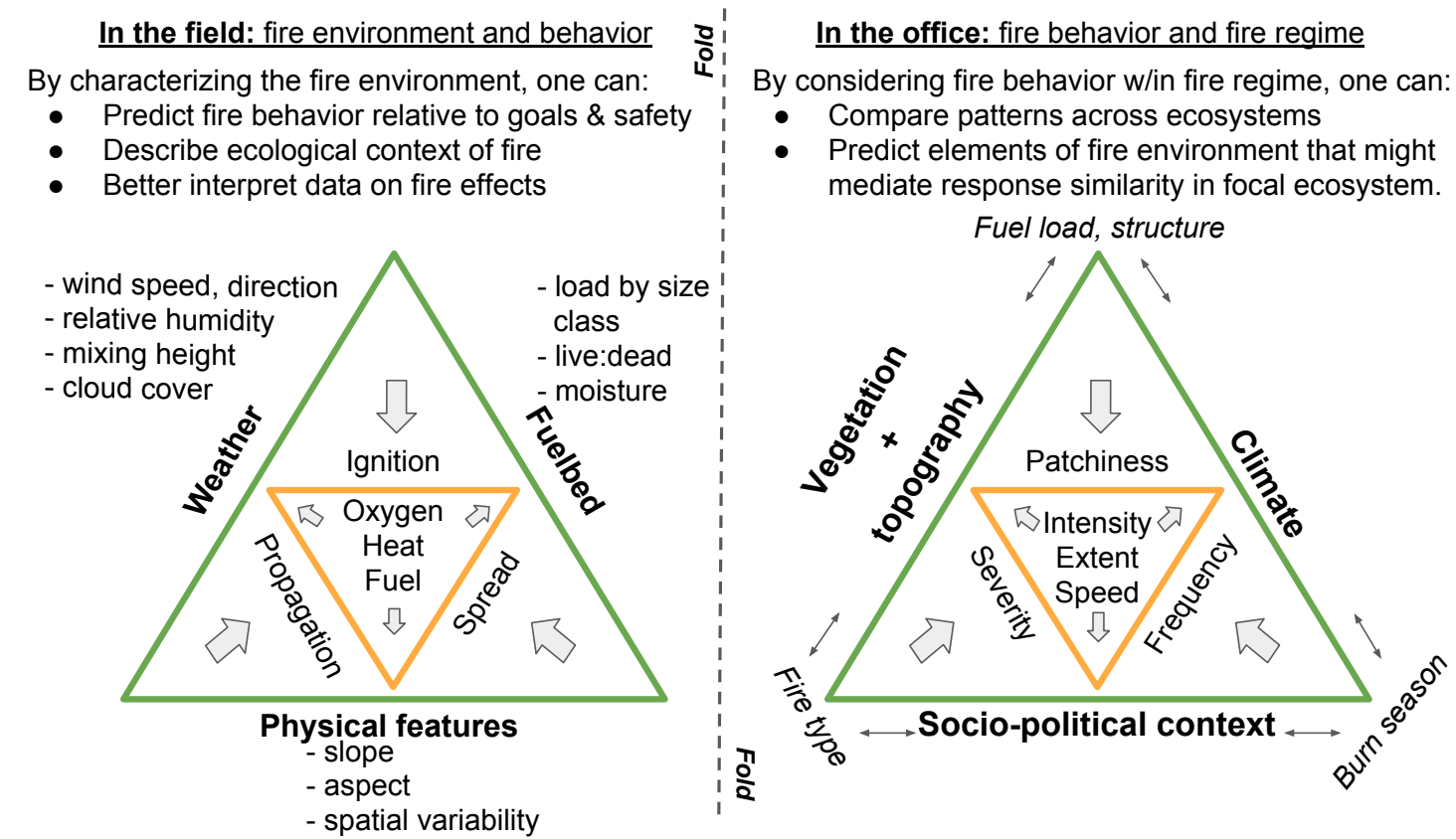

Figure 2. Wildland fire science is practiced in two arenas-the field and the office-but few wildland fire professionals are confined to a single arena; they must both focus on relevant components of their specialty and translate this perspective to those with other specialties. This wallet card promotes fire science literacy by helping fire professionals from each arena identify characteristics of the fire environment or fire regime that dominate their colleagues' perspective. The "wallet card" idea is a bit tongue-in-cheek, but what can it hurt to put this card in your pocket or above your desk?

\section{Conclusions}

Wildland fire science has progressed from the relatively narrow applications of wildfire suppression based on steady-state models into a multidisciplinary field that seeks to describe and manage variability at multiple scales in a complex socio-ecological context. While conventional frameworks for wildland fire science encompass most sources of biotic and abiotic variability in the wildland fire environment, many such models fail to incorporate the human dimensions of wildland fire (e.g., Figure 1). The development of wildland fire science literacy enhances the capacity of wildland fire professionals to learn, create, and apply the fundamentals of wildland fire science in a dynamic socio-ecological context. Our conceptual model for wildland fire science literacy resolves two arenas of practice - the field and the office - and highlights essential components of the socio-ecological fire regime that facilitates communication between the arenas and enhances the generation and application of robust fire science for learners, researchers, managers, and policymakers alike.

Author Contributions: Conceptualization, D.A.M. and C.L.W.; writing, original draft preparation, D.A.M.; writing, review and editing, C.L.W.; writing, revision, D.A.M. and C.L.W.

Funding: This research received no external funding.

Conflicts of Interest: The authors declare no conflict of interest. 


\section{References}

1. Yedinak, K.; Strand, E.; Hiers, J.; Varner, J. Embracing Complexity to Advance the Science of Wildland Fire Behavior. Fire 2018, 1, 20. [CrossRef]

2. Scott, A.C.; Bowman, D.M.; Bond, W.J.; Pyne, S.J.; Alexander, M.E. Fire on Earth: An Introduction; John Wiley \& Sons: Chichester, UK, 2013.

3. Vare, P.; Scott, W. Learning for a Change: Exploring the Relationship between Education and Sustainable Development. J. Educ. Sustain. Dev. 2007, 1, 191-198.10.1177/097340820700100209. [CrossRef]

4. Colucci-Gray, L.; Camino, E.; Barbiero, G.; Gray, D. From Scientific Literacy to Sustainability Literacy: An Ecological Framework for Education. Sci. Educ. 2006, 90, 227-252. [CrossRef]

5. Sullivan, A.L. Inside the Inferno: Fundamental Processes of Wildland Fire Behaviour: Part 1: Combustion Chemistry and Heat Release. Curr. For. Rep. 2017, 3, 132-149.10.1007/s40725-017-0057-0. [CrossRef]

6. Sullivan, A.L. Inside the Inferno: Fundamental Processes of Wildland Fire Behaviour: Part 2: Heat Transfer and Interactions. Curr. For. Rep. 2017, 3, 150-171.10.1007/s40725-017-0058-z. [CrossRef]

7. Rothermel, R.C. How to Predict the Spread and Intensity of Forest and Range Fires; Technical Report General Technical Report INT-143; United States Department of Agriculture, Forest Service: Ogden, UT, USA, 1983; p. 161.

8. Finney, M.A.; Cohen, J.D.; McAllister, S.S.; Jolly, W.M. On the Need for a Theory of Wildland Fire Spread. Int. J. Wildland Fire 2013, 22, 25-36.10.1071/WF11117. [CrossRef]

9. Steelman, T. US Wildfire Governance as Social-Ecological Problem. Ecol. Soc. 2016, 21, 4. [CrossRef]

10. Kyburz-Graber, R.; Hofer, K.; Wolfensberger, B. Studies on a Socio-Ecological Approach to Environmental Education: A Contribution to a Critical Position in the Education for Sustainable Development Discourse. Environ. Educ. Res. 2006, 12, 101-114. [CrossRef]

11. Moritz, M.A.; Batllori, E.; Bradstock, R.A.; Gill, A.M.; Handmer, J.; Hessburg, P.F.; Leonard, J.; McCaffrey, S.; Odion, D.C.; Schoennagel, T. Learning to Coexist with Wildfire. Nature 2014, 515, 58-66. [CrossRef] [PubMed]

12. Kyburz-Graber, R. Socioecological Approaches to Environmental Education and Research. In International Handbook of Research on Environmental Education; Stevenson, R., Brody, M., Dillon, J., Wals, A., Eds.; Routledge: New York, NY, USA; Abingdon, UK, 2013; pp. 23-32.

13. Brinson, J.R. Learning Outcome Achievement in Non-Traditional (Virtual and Remote) versus Traditional (Hands-on) Laboratories: A Review of the Empirical Research. Comput. Educ. 2015, 87, 218-237.10.1016/j.compedu.2015.07.003. [CrossRef]

14. Reuter, R. Online versus in the Classroom: Student Success in a Hands-on Lab Class. Am. J. Distance Educ. 2009, 23, 151-162.10.1080/08923640903080620. [CrossRef]

15. Cottingham, K.L.; Lennon, J.T.; Brown, B.L. Knowing When to Draw the Line: Designing More Informative Ecological Experiments. Front. Ecol. Environ. 2005, 3, 145-152. [CrossRef]

16. Smith, A.M.; Sparks, A.M.; Kolden, C.A.; Abatzoglou, J.T.; Talhelm, A.F.; Johnson, D.M.; Boschetti, L.; Lutz, J.A.; Apostol, K.G.; Yedinak, K.M.; et al. Towards a New Paradigm in Fire Severity Research Using Dose-Response Experiments Int. J. Wildland Fire 2016, 25, 158-166.10.1071/WF15130. [CrossRef]

17. Foster, C.N.; Sato, C.F.; Lindenmayer, D.B.; Barton, P.S. Integrating Theory into Disturbance Interaction Experiments to Better Inform Ecosystem Management. Glob. Chang. Biol. 2016, 22, 1325-1335.10.1111/gcb.13155. [CrossRef] [PubMed]

18. Gurevitch, J.; Curtis, P.S.; Jones, M.H. Meta-Analysis in Ecology. Adv. Ecol. Res. 2001, 32, $199-247$.

19. Diamond, J.M.; Call, C.A.; Devoe, N. Effects of Targeted Cattle Grazing on Fire Behavior of Cheatgrass-Dominated Rangeland in the Northern Great Basin, USA. Int. J. Wildland Fire 2009, 18, 944.10.1071/WF08075. [CrossRef]

20. Bowman, D.M.J.S.; Balch, J.; Artaxo, P.; Bond, W.J.; Cochrane, M.A.; D’Antonio, C.M.; DeFries, R.; Johnston, F.H.; Keeley, J.E.; Krawchuk, M.A.; et al. The Human Dimension of Fire Regimes on Earth. J. Biogeogr. 2011, 38, 2223-2236.10.1111/j.1365-2699.2011.02595.x. [CrossRef] [PubMed]

21. Kuuluvainen, T. Conceptual Models of Forest Dynamics in Environmental Education and Management: Keep It as Simple as Possible, but No Simpler. For. Ecosyst. 2016, 3.10.1186/s40663-016-0075-6. [CrossRef] 
22. Engle, D.M.; Bidwell, T.G. The Response of Central North American Prairies to Seasonal Fire. J. Range Manag. 2001, 54, 2-10. [CrossRef]

23. Towne, E.G.; Craine, J.M. Ecological Consequences of Shifting the Timing of Burning Tallgrass Prairie. PLoS ONE 2014, 9, e103423. [CrossRef] [PubMed]

(C) 2018 by the authors. Licensee MDPI, Basel, Switzerland. This article is an open access article distributed under the terms and conditions of the Creative Commons Attribution (CC BY) license (http://creativecommons.org/licenses/by/4.0/). 